\title{
Educação em Direitos Humanos na Perspectiva de \\ Adolescentes Participantes de um Projeto Social
}

Franciéli Katiúça Teixeira da Cruz Severo ${ }^{1}$

${ }^{1}$ Universidade Feevale, RS, Brasil.

\author{
Carmem Regina Giongo ${ }^{1}$
}

${ }^{1}$ Universidade Feevale, RS, Brasil.

Elina Perez Gonçalves de Moura ${ }^{1}$

${ }^{1}$ Universidade Feevale, RS, Brasil.

Resumo: Este artigo possui o objetivo de analisar e discutir as interfaces entre Psicologia e Educação em Direitos Humanos a partir do relato de uma intervenção, na modalidade de oficinas, desenvolvida com adolescentes participantes de um projeto social na região metropolitana de Porto Alegre. Os participantes integrantes do projeto social foram 15 adolescentes de diferentes graus de formação escolar, com idade média de 13,9 anos. Do ponto de vista da produção e coleta de informações, foram utilizadas duas estratégias: aplicação de questionários antes e depois da realização dos cinco encontros e adoção de diário de campo para o registro das informações coletadas em cada oficina. O conteúdo do diário de campo e dos questionários foi analisado a partir da técnica de análise temática. A realização dos encontros permitiu evidenciar realidades de violação dos direitos humanos dos adolescentes, bem como os efeitos da intervenção na vida dos mesmos e as possibilidades de atuação da Psicologia nesses contextos. Além disso, ressalta-se a importância de construir oficinas de Educação em Direitos Humanos junto a grupos de adolescentes como uma estratégia de fomento do compartilhamento de possíveis situações de violações entre os participantes e uma forma de reconhecimento de demandas dessa natureza.

Palavras-chave: Psicologia, Adolescentes, Educação em Direitos Humanos.

\section{Education in Human Rights under the Perspective of Adolescents Participating in a Social Project}

\begin{abstract}
This article aims to analyze and discuss the interfaces between Psychology and Human Rights Education based on the reports of adolescents participating in a workshop-based intervention in the metropolitan region of Porto Alegre. Fifteen adolescents with average age of 13.9 years and different school backgrounds, members of the social project, participated in the study. Data were collected using questionnaires applied before and after the five meetings and field diaries for each of the workshop sessions, and analyzed by means of thematic analysis. The meetings evinced experiences of violation of the human rights of the adolescents, as well as the effects of the intervention in their lives and possible actions promoted by the field of Psychology within this context. This study highlights the importance of developing workshops on Human Rights Education with groups of adolescents as a strategy to share possible violations experienced by participants and to recognize this type of demands.
\end{abstract}

Keywords: Psychology, Adolescents, Education in Human Rights. 


\title{
Educación en Derechos Humanos en la Perspectiva de Adolescentes Participantes en un Proyecto Social
}

\begin{abstract}
Resumen: Este artículo tiene como objetivo analizar y discutir las interfaces entre Psicología y Educación en Derechos Humanos a partir del relato de una intervención, en la modalidad de talleres, desarrollada con adolescentes participantes de un proyecto social en la región metropolitana de Porto Alegre. En este estudio, participaron 15 adolescentes integrantes del proyecto social que estaban en distintos grados de la enseñanza básica y tenían edad promedio de 13,9 años. Con respecto a la producción y recolección de datos, se utilizaron dos estrategias: aplicación de cuestionarios antes y después de los cinco encuentros, y uso de diario de campo para el registro de los datos recolectados en cada taller. Para el análisis, el contenido del diario de campo y de los cuestionarios fueron analizados desde la técnica del análisis temático. La realización de los encuentros permitió evidenciar realidades de violación de los derechos humanos de los adolescentes, así como los efectos de la intervención en sus vidas y las posibilidades de actuación de la Psicología en estos contextos. Además, se resalta la importancia de desarrollar talleres de Educación en Derechos Humanos con grupos de adolescentes como estrategia de fomento del proceso de compartir posibles situaciones de violaciones entre los participantes y como forma de reconocimiento de demandas de esa naturaleza.
\end{abstract}

Palabras clave: Psicología, Adolescentes, Educación en Derechos Humanos.

Apesar de os direitos do homem serem discutidos desde a Antiguidade, foi apenas a partir da Revolução Francesa que a concepção de "diretos humanos” passou a ter evidência na história. No período do Iluminismo, a dignidade humana passou a ser algo importante, contribuindo para a luta em busca do reconhecimento e da legitimação dos princípios dos direitos humanos (Bernardi, 2010). Esses direitos foram fundados em lugares improváveis e com intenções questionáveis, uma vez que, como descreve Hunt (2009), nos primórdios dessa história, aqueles que declaravam os direitos eram os mesmos que excluíam os escravos, os negros e as mulheres.

Nesse sentido, a ideia de direitos humanos é moderna na sociedade ocidental, sendo propagada com mais intensidade a partir das catastróficas violações ocorridas na Segunda Guerra Mundial (Rosato, 2011). As violências e atrocidades cometidas contra a humanidade, como a busca pela eugenia comandada por Hitler, a bomba atômica e o desenvolvimento bélico estadunidense, segundo Bernardi (2010), validaram a atuação do Estado como um dos maiores violadores dos direitos humanos. Então, as "feridas" marcadas por essas grandes tragédias demandaram a criação de um instrumento internacional que garan- tisse a proteção de qualquer pessoa, instaurando uma nova perspectiva de direitos humanos na sociedade atual. Teve início um longo e necessário trabalho, cujos principais objetivos foram a promoção e a proteção da pessoa humana (Dallari, 2008).

Em 1945, foi criada a Organização das Nações Unidas (ONU) com o intuito de manter a paz e a segurança mundial. Em seguida, em 1948, instituiu-se a Declaração Universal dos Direitos Humanos (DUDH), que atua como dispositivo de regulação da ação de todos os Estados e de normatização da proteção internacional dos direitos (Rosato, 2011). Por conseguinte, desde então, a DUDH afirma que todos, sem exceção, nascem livres e iguais e que toda Constituição ou sistema legal que contiver exclusões e discriminações quantos aos direitos humanos não possui valor jurídico legal (Dallari, 2008).

O conceito moderno de direitos humanos se consagra com a definição de universalidade, indivisibilidade e interdependência dos direitos. A universalidade define todos os seres humanos como pessoas titulares de direitos, considerando-os essencialmente morais, únicos e dignos. A indivisibilidade se refere à necessidade de garantia dos direitos civis e políticos para o efetivo cumprimento dos direitos sociais, econômicos 
e culturais, reciprocamente. Por fim, a interdependência remete ao fato de que esses direitos compõem uma unidade indivisível, pois quando um direito é violado, os demais também são (Piovesan, 2004).

Diante do contexto de concepção dos direitos humanos no Brasil, é possível perceber que tal temática sempre mobilizou defesas e ataques, sendo os movimentos populares os grandes protagonistas dessa luta. Assim, enquanto esses movimentos protagonizavam a luta pela garantia dos direitos, alguns representantes da elite brasileira buscavam estratégias a fim de enfraquecê-los e, dessa maneira, impedir a propagação do conhecimento sobre o que seria garantido através de tais direitos. Nesse campo de lutas, entre defesas e ataques, surge a educação em direitos humanos, servindo como instrumento de institucionalização de uma cultura para a garantia dos direitos. O desenvolvimento dessa área foi possibilitado pela articulação das políticas de educação, consolidadas nas Diretrizes e Bases da Educação, e das políticas do Plano Nacional de Direitos Humanos (Tavares, 2013).

Destarte, a luta pela consolidação dos direitos humanos se estende à psicologia como ciência e profissão, que aos poucos tem se ocupado de diversos espaços de discussão em torno dos direitos, por exemplo, das crianças e dos adolescentes, de igualdade de gênero, da Reforma Psiquiátrica e dos debates sobre sistema prisional. Entretanto, para que isso ocorra, é necessário o comprometimento do psicólogo com as propostas de transformações sociais, pois embora exista possibilidade de participação efetiva da psicologia nos espaços de denúncias, debates, enfrentamentos e concretização de direitos e cidadanias, percebe-se pouca atuação dos psicólogos nesses espaços (Costa, Oliveira, \& Ferrazza, 2014).

Dessa forma, é importante que, mesmo paulatinamente, a psicologia afirme e solidifique sua atuação pautada nos ideais de direitos humanos e, segundo Rosato (2011), também se atente às condições sociais dos sujeitos, afinal, as sistemáticas violações de direitos são normalmente causa de sofrimentos e adoecimento psíquico das populações. Na perspectiva de Bock e Gianfaldoni (2010), a psicologia tem o compromisso de se desenvolver academicamente a partir de uma ética em direitos humanos para, então, contribuir com o avanço da cultura de direitos, pois é fundamental, no âmbito da psicologia, que os sujeitos com os quais o profissional trabalha e os indivíduos pesquisados sejam sempre concebidos como "sujeitos de direitos". Portanto, cabe aos profissionais da área a compreensão, o conhecimento e o compromisso ético de articular a prática profissional aos direitos humanos, aspecto que é observado neste estudo.

Este artigo tem como objetivo analisar e discutir as interfaces entre a psicologia e a educação em direitos humanos a partir do relato de uma intervenção, na modalidade de oficinas, desenvolvida com adolescentes participantes de um projeto social. Tal iniciativa atua em função de oportunizar a inclusão social e promover a cidadania de crianças e adolescentes de escolas públicas através de práticas esportivas. $\mathrm{O}$ projeto está distribuído por núcleos, contemplando cinco bairros de periferias de uma das cidades da região metropolitana de Porto Alegre (RS). As aulas do projeto ocorrem duas vezes por semana em dias alternados, e cada núcleo contempla cinco turmas distribuídas por idade, com, em média, 20 alunos cada.

\section{Metodologia}

Este estudo foi construído após a inserção de uma das autoras como estagiária de psicologia social em um projeto social desenvolvido na região do Vale dos Sinos, no Rio Grande do Sul. O projeto tem aproximadamente 500 alunos, com idades entre 7 e 16 anos, e se propõe a realizar atividades esportivas em cinco núcleos distribuídos nos bairros de periferia da cidade. Durante o período do estágio, os adolescentes participantes foram acompanhados pela estagiária em um Fórum Municipal de Direitos Humanos, situação na qual observou-se o desconhecimento dos jovens em relação à temática. Evidenciou-se, então, uma demanda que resultou na construção e condução de oficinas de educação em direitos humanos com os adolescentes vinculados ao projeto. O trabalho ocorreu entre maio e junho de 2017, totalizando cinco encontros semanais. As oficinas foram oferecidas no anexo do ginásio de esportes localizado em um dos bairros (núcleos) da cidade, onde ocorrem as aulas do projeto.

Participaram das oficinas 15 adolescentes, dez deles estudantes da $8^{a}$ série do Ensino Fundamental e cinco deles estudantes da 9a série do Ensino Fundamental, com idades entre 13 e 18 anos (média de 13,9), todos integrantes do projeto social e moradores das proximidades de onde o projeto é desenvolvido. O convite para participar da atividade foi estendido aos adolescentes de apenas um dos núcleos, que foi escolhido por critério 
de conveniência. Como recursos metodológicos, foram utilizados o diário de campo e a aplicação de dois questionários. O diário de campo visou "retratar os procedimentos de análise do material empírico, as reflexões e as decisões na condução das oficinas"(Araújo et al., 2013, p. 54). Dois questionários com questões abertas e fechadas foram aplicados. O questionário inicial foi aplicado no primeiro dia do encontro e o Questionário Final no último encontro. $\mathrm{O}$ primeiro continha 17 questões, dez delas com o objetivo de identificar as características dos participantes e conhecer suas implicações acerca da temática dos direitos humanos. O questionário final, aplicado no último encontro, possuía apenas 7 questões sobre os conhecimentos e as implicações dos participantes acerca do tema.

Os dados descritos no diário de campo e coletados pelos questionários foram analisados por meio da metodologia de Análise Temática (Minayo, 2001). Em relação aos aspectos éticos, destaca-se que o presente estudo passou pela avaliação do Comitê de Ética e Pesquisa (CEP) da Universidade Feevale, recebendo a devida aprovação para a execução, expressa no parecer de n. ${ }^{\circ}$ 2.340.904. Além disso, foi esclarecida a natureza, os procedimentos e os objetivos desta pesquisa ao projeto social e aos participantes do estudo. Os pesquisadores também se comprometeram a preservar a privacidade dos adolescentes, fazendo a divulgação dos resultados do trabalho somente de forma anônima.

\section{Análise e discussão dos resultados}

A partir da análise dos materiais obtidos, os resultados serão apresentados em três eixos temáticos de discussão: a) "A escola que viola: interlocuções entre os ideais e a realidade", que visa apresentar as demandas e implicações dos participantes em face da temática; b) "Projetos sociais: a negação de uma educação em direitos humanos", que busca problematizar o papel dos projetos sociais e da educação em direitos humanos; e c) "Ensaios de um despertar: por onde começa a transformação?”, que visa compartilhar alguns efeitos e desafios da prática da psicologia no contexto social.

\section{A escola que viola: interlocuções entre os ideais e a realidade}

A gente não concorda, muitas vezes, com o que os professores e as tias da limpeza e da cozinha falam, mas a gente não pode fazer nada, nossa opinião não vale nada. Lá na escola, os professores sempre têm razão, e ponto final. Não temos chance de mudar algo. Sempre os alunos se dão mal. Eles marcam a gente! (Participante 1, diário de campo, 5 de junho de 2017).

Diante da fala desse participante, pretende-se articular uma breve reflexão referentemente àquilo que os adolescentes compartilharam como uma de suas principais demandas em relação à temática de direitos humanos. É necessário ressaltar, nesse contexto, que a escola se tornou o principal cenário citado pelos participantes, pois praticamente todas as vivências relatadas aconteceram nesse local. Assim, ao reconhecer os direitos e deveres, o que mais angustiava o grupo era não ter voz enquanto alunos.

O autor Veiga-Neto (2006) traz à luz, em um de seus estudos sobre a educação, uma reflexão sobre aquilo que é histórico em nossa humanidade: a atual ideia de libertação e transformação do homem através do conhecimento e a existência de um mundo ideal que poderia ser alcançado por meio dele. Percebe-se que, ao pensar em conhecimento, de modo geral, há uma indução "natural" de relacioná-lo à educação e à escola. Segundo Moura e Zucchetti (2010), é comum conceber a educação como exclusivamente atrelada à escola enquanto espaço de disseminação de conhecimento, pois trata-se de uma instituição socialmente legitimada e proprietária do direito (e dever) à transmissão de conhecimentos.

Com base nessas concepções, é necessário investigar como foram criadas as verdades nesse ambiente, quais são os efeitos produzidos por elas e, se necessário, como elas podem ser alteradas com o intuito de mudar seus efeitos (Veiga-Neto, 2006). É, portanto, preciso atentar para os efeitos que essas verdades sobre o conhecimento e a educação produzem nos contextos escolares, sendo, por vezes, contextos responsáveis por violações de direitos humanos. Nesse panorama, as violações ocorrem justamente nos locais legitimados pelos princípios de liberdade, solidariedade e exercício da cidadania. Conforme regulamentado na Lei das Diretrizes e Bases da Educação, a educação "tem por finalidade o pleno desenvolvimento do educando, seu preparo para o exercício da cidadania e sua qualificação para o trabalho" (Lei n. $9.394,1996$, art. $2^{\circ}$ ).

Além disso, é comum que, ao se discutir temas associados à violação de direitos humanos e educa- 
ção, emerjam debates relativos à exclusão escolar, como falta de escola para todos. Porém, "nem sempre a exclusão se resume ao fato de que a criança está fora do espaço físico da escola, refere-se também ao estar fora do espaço simbólico da cultura e da economia" (Dazzani, 2010, p. 365). Nesse sentido, é necessário ampliar o leque de discussões e adentrar as paredes das escolas enquanto instituições legitimadas socialmente pela efetivação da educação, refletindo sobre as "verdades" construídas no decorrer dos anos.

O pensamento naturalizado de atribuição das práticas de conhecimento e educação unicamente à escola espelha um dos grandes conflitos geradores de violações no contexto escolar. Afinal, considera-se, aqui, a educação como um processo de interação que ocorre o tempo todo, inclusive no convívio em sociedade (Maturana, 1999). Buscando conceitualizar a educação como um processo, um fato existencial, social e cultural, Pinto (1987, citado por Gadotti, 1993, grifos do autor) explica que a educação representa a própria história individual de cada ser humano, sendo a forma do "homem se fazer ser homem" em si, e não diante daquilo a que ele é submetido. $O$ autor complementa afirmando que a educação está vinculada à fase vivida pela comunidade em que o homem se insere, ao mesmo tempo em que a comunidade é movida pelos interesses de seus próprios membros, que permanecem em um processo de contínua evolução.

Apesar disso, a educação construída na escola contemporânea valoriza quase que exclusivamente os conhecimentos e as habilidades consideradas necessárias nos setores produtivos da economia capitalista (Moura \& Zucchetti, 2010). Consequentemente, a escola acaba, muitas vezes, por transmitir aos alunos a percepção de que valores culturais de determinados grupos estão corretos, tendo como critério determinadas ações pautadas na qualificação da mão de obra para o mercado de trabalho. Sendo assim, os principais benificiários da escola, os alunos, não encontram nesse local a valorização e o reconhecimento de seus conhecimentos sociais e culturais (Dazzani, 2010).

Para Veiga-Neto (2006), apesar de a escola funcionar como uma instituição capaz de articular o poder com o saber, ela corre o risco de se tornar uma "arena para as lutas permanentes de invenção e imposição de sentidos, seja pela manutenção, seja pela mudança dos regimes de verdade e das ordens discursivas que os alojam" (Veiga-Neto, 2006, p. 9). No contexto das oficinas, a escola se tornou a grande protagonista dos encontros, pois os participantes revelaram situações de violações vivenciadas cotidianamente no ambiente escolar. Dentre as violações compartilhadas, foram observados desde o desrespeito e a violência entre professores e alunos, ou mesmo entre alunos, até a negação da escola em oportunizar espaços para a discussão da temática direitos humanos.

Para exemplificar, seguem alguns trechos de discussões ocorridas no terceiro encontro das Oficinas de Educação em Direitos Humanos, quando debateu-se o direito à educação:

Ah, sora. Essa professora lá da escola nos chamou de 'merda' na aula e disse que a gente não estuda em final de semana como a filha dela. Disse que quando crescermos vamos todos ser serviçais da filha dela. Só porque a filha dela estuda em uma escola caríssima e vai ser muito bem-sucedida, diferente da gente, que não queremos nada da vida. Ela nem sabe o que a gente faz, não sabe se eu estudo em casa ou não. Por que ela pensa que pode falar isso de mim? Quem disse que eu não quero nada da vida? E a professora falou que vamos ter que esfregar o chão se a filha dela mandar, porque não temos competência para nada. Tudo isso só porque alguns não leram um texto que ela mandou (Participante 3, diário de campo, 12 de junho de 2017).

Logo em seguida, outra participante comentou:

Essa professora já chamou meu irmão de 'marginal' na aula. E disse que nós também estamos nos tornando isso. Os professores vivem implicando com o jeito dele, que não sabe se comportar, falar, todas essas coisas, sabe? Ele tem tanta raiva dela que jogou uma classe nela no dia em que ela chamou ele de 'marginal'! (Participante 4, diário de campo, 12 de junho de 2017).

Com base no exposto, verifica-se uma discrepância no que se refere à relação esperada entre educação e escola, demonstrando que, nas vivências dos alunos participantes das oficinas, a educação escolar não tem atuado enquanto promotora de autonomia e cidadania, mas pautada na lógica da disciplina, da ordem e do capital. Essas divergências tornam o ambiente esco- 
lar um cenário de despercebidas violações, as quais se instauram tanto sobre os alunos quanto sobre os professores. Para Gallo (2004), os professores são formados da mesma maneira, apenas reproduzindo modelos enquanto profissionais. Percebe-se que a educação proposta pelas escolas ocorre fora do "mundo real" desses alunos, destituindo-os do sentimento de pertencimento àquele espaço. É como se fosse necessário lutar para ocupar um lugar dito "seu", utilizando, para isso, indeterminadas ferramentas. Nesse sentido, Iamamoto (2004) afirma que garantir os direitos humanos é um grande desafio, pois é necessário:

atribuir visibilidade e transparência a esses sujeitos de direitos: o seu modo de vida, cultura, padrões de sociabilidade, dilemas de identidades, suas necessidades, suas lutas pelo reconhecimento efetivo da cidadania, seus sonhos e esperanças, afirmando o direito de ser criança para aqueles que vivem a experiência de uma infância negada e de uma juventude desenraizada (Iamamoto, 2004, p. 265).

Além das questões relacionadas à valorização e ao reconhecimento dos modos de vida e compartilhamento de experiências na escola, Mattos (2003) comenta outros aspectos a serem observados no contexto escolar. Para o autor, a escola brasileira ainda se caracteriza como um espaço de reprodução da cultura da violência, da desigualdade, de exclusão "da" e "na" escola, do privilegiamento do "eu" sobre o "nós", da tomada de decisões sobre o funcionamento muitas vezes restrito à equipe diretiva, descomprometida com a construção da não violência, da cidadania, de sujeitos críticos, éticos e transformadores da vida escolar e da sociedade como um todo. Alguns desses pontos apontados pelo autor foram relatados ainda no terceiro encontro das oficinas:

Ah, eu sou presidente do Grêmio Estudantil da escola e eu já fui perguntar para a diretora se pode mudar isso, e ela disse que não. Ela disse a mesma coisa quando eu fiz um levantamento com os alunos e nós decidimos que teria que pintar a escola. Ela sempre diz que não temos que nos meter, porque quem não paga CPM não deve dar nenhuma sugestão na escola, tem que ficar quieto. Mas muitos pagam CPM. (Participante 5, diário de campo, 12 de junho de 2017).
Nas palavras de outro participante, a professora apontou o seguinte:

'Vocês acham que o governo está se importando com vocês? Vocês não têm importância nenhuma, e essas greves nunca levaram a nada, principalmente se for vocês, porque vocês não são nada para o governo porque não votam, vocês não dão voto para ninguém' (Participante 4, diário de campo, 12 de junho de 2017).

Os participantes falaram sobre seus sentimentos de impotência, compartilhando sua "quase nula" participação nas decisões, na discussão dos projetos e nas situações cotidianas da escola, contrariando a prescrição da própria legislação dos sistemas de ensino. O direito à liberdade de reuniões e associações está garantido pela DUDH, mas mesmo participando do grêmio estudantil os alunos se sentiam destituídos do direito de participação. Sobre essa perspectiva, é necessário recorrer novamente à Lei de Diretrizes e Bases da Educação (Lei no ${ }^{\circ} .394$, de 20 de dezembro de 1996), que enfatiza um ensino pautado na gestão democrática através da participação dos educadores na construção do projeto político pedagógico da escola e do envolvimento da comunidade escolar em conselhos e atividades similares.

Portanto, cabe pensar: o que seria uma escola com uma gestão democrática? De que forma esse pressuposto contribuiria no contexto da escola atual? Não se pretende, com esse parágrafo, responder a esses questionamentos, principalmente porque, ao evocar um modelo democrático, parte-se do princípio de que cada escola e comunidade deverão definir sua concepção sobre essa forma de gestão. Porém, partindo das situações evidenciadas nessas entrelinhas, é possivel pensar em algumas contribuições acerca da participação da comunidade escolar e local (representantes dos alunos e dos bairros) nas decisões da instituição.

Contudo, para que ocorra uma democratização da escola e, consequentemente, a promoção dos direitos humanos, é necessário que esses processos se desenvolvam de maneira crítica e conjunta, partindo da premissa de que a escola é um espaço vivamente plural e interdisciplinar. Assim, permite-se a valorização dos conhecimentos locais, dos modos de ser e existir relativos à própria existência e à produção do saber daquela comunidade, e não "a disputa e conflitos de saberes dos professores, dos técnicos, dos 
alunos, dos pais, da comunidade e, frequentemente, das vozes de outros profissionais envolvidos na ação educativa" (Dazzani, 2010, p. 371).

Por fim, é indispensável que haja espaço para elaboração do coletivo e das diversas realidades nos ambientes escolares, além de para a mobilização diante do que se apresenta incontestável, ocorrendo a destituição do saber preexistente. É preciso compreender que uma educação que não viola é aquela que não massifica e mercantiliza os alunos, mas sim os possibilita construir e reconstruir sua própria realidade. A educação que não viola é aquela que é convicta de que a mudança é possível, constatando esse fato não para se adaptar, mas sim para mudar (Freire, 1997). Afinal, "o mundo não é. O mundo está sendo” (Freire, 1997, p. 95), de forma única para cada um que nele existe.

\section{Projetos sociais: a negação de uma educação em direitos humanos}

Apesar de conhecer as leis que garantem a promoção da educação em direitos humanos nos locais de educação formal (escolas) e não formal (projetos sociais), conforme descrito no Plano Nacional de Educação em Direitos Humanos (PNEDH), percebe-se, através dessa experiência, que tanto a escola quanto os projetos sociais aos quais os participantes das oficinas estavam vinculados não vêm se comprometendo a oportunizar esses espaços de fala. Durante o primeiro encontro, os participantes das oficinas relataram que não sabiam o que eram os direitos humanos, como pode ser observado no relato da pesquisadora.

Após este momento de preenchimento dos questionários, surgiram vários 'não sei'. Foi necessária uma mudança repentina no roteiro do grupo, pois o grupo foi construído na expectativa de que os alunos saberiam ou teriam alguma ideia sobre o tema, já que a maioria participava do projeto social fazia tempo. (Pesquisadora, diário de campo, 15 de maio de 2017).

Corroboram essa discussão os dados verificados a partir do preenchimento do primeiro questionário, pois dos 15 participantes do primeiro encontro com o grupo, dez marcaram a opção "não" ao serem questionados se já ouviram falar sobre direitos humanos. Entre os demais participantes, dois responderam que já ouviram falar sobre televisão e os outros três responderam que já ouviram o termo na aula de religião da escola. Apesar de cinco alunos marcarem a opção "sim", afirmando que ouviram falar sobre o tema, apenas uma das participantes soube explicar a que se referia. Além disso, em uma das perguntas do questionário, os participantes foram questionados sobre em quais lugares buscariam ajuda se tivessem um direito violado, e dez dos 15 participantes responderam que não sabiam, não reconhecendo o projeto social como um espaço de manifestação e reivindicação de seus direitos.

Diante disso, faz-se necessário dialogar sobre as origens dos projetos sociais, sua relação com a educação e suas interlocuções atuais. Historicamente, tanto os projetos sociais quanto as Organizações Não Governamentais (ONG) fazem parte do chamado terceiro setor, que surgiu, dentre outros motivos, da tentativa de reduzir as desigualdades sociais do Brasil. Segundo Souza (2006), o universo do terceiro setor é extremamente heterogêneo, pois se refere a qualquer organização privada sem fins lucrativos de diferentes segmentos e grupos sociais. Surgiu na década de 1990 com o discurso de humanizar o capitalismo a partir da renovação do espaço público, do resgate da solidariedade e da cidadania, bem como da superação da pobreza. Pretendia-se realizar essa promessa "através de atos simples e fórmulas antigas, como o voluntariado e a filantropia, revestidas de uma roupagem mais empresarial" (Falconer, 1999, p. 57).

Além disso, os projetos sociais se afirmam com a promessa de construir um espaço público para que os desiguais possam encontrar em condições de igualdade, um lugar para se manifestar e reivindicar seus direitos. Nesse contexto, com ações voltadas para a cidadania e a solidariedade, os projetos sociais que atendem crianças e adolescentes têm, em seu discurso, um compromisso com o protagonismo juvenil e com o objetivo de tornar o jovem um "ator social", comprometido com a luta e a garantia dos seus direitos enquanto cidadão.

Porém, já faz alguns anos que a militância dos projetos sociais e das ONG vem cedendo espaço para a adequação e a qualificação profissional. O perfil atual do jovem que é atendido nesses locais não é mais aquele com posição política firmada, detentor de um passado de lutas em prol do movimento popular; trata-se predominantemente do jovem recém-formado que inicia sua carreira no mercado de trabalho (Landim, 1993; Moura \& Zucchetti, 2010). Como con- 
sequência, os antigos ideais vêm sendo substituídos pela profissionalização e pela adoção de uma administração empresarial com ênfase na produtividade e na eficácia (Charão, 2001). Assim, há poucos espaços para discutir realmente questões ligadas à cidadania e à solidariedade como proposto nos discursos dos projetos sociais. Percebe-se esse fato por meio do relato dos participantes, como nas palavras de um jovem ao ser questionado sobre o que achou das oficinas: "Achei muito interessante tudo isso. Precisamos ter mais momentos de conversas como essas" (Participante 5, comunicação pessoal, 29 de maio de 2017).

Outro aspecto a ser considerado é que os projetos são pensados "para" os participantes, e não mais "com" eles. Não há espaço para a utilização do saber anterior dos jovens nem valorização da diversidade e da heterogeneidade do grupo envolvido nos projetos. Nesse sentido, fica evidenciada a "escolarização" dos projetos sociais, pois a mesma situação que acontece na educação escolar, na qual as experiências sociais e os conhecimentos locais dos jovens são desvalorizados, parece acontecer no contexto dos projetos sociais. Em suma, percebe-se que ambos os espaços estão comprometidos com as práticas de produzir "sujeitos civilizados", bons cidadãos e dóceis trabalhadores (Moura \& Zucchetti, 2010).

Essa dicotomia que tange à história e à realidade dos projetos sociais não é um fato identificado de forma clara, sendo quase sempre algo despercebido pelos profissionais que trabalham nesses locais e, principalmente, por aqueles que participam dos projetos. Porém, o desconhecimento dos objetivos históricos e atuais dos projetos sociais é um fator responsável por diversas dificuldades que os profissionais enfrentam quando buscam pensar ações nesse contexto. Sendo assim, conhecer a realidade nem sempre evidenciada nos projetos sociais permite refletir sobre algumas questões desafiadoras e emergentes neles presentes. Diante dessa dicotomia, cabem os seguintes questionamentos: o que seria um jovem protagonista? Como tornar o jovem um sujeito protagonista? Qual é a responsabilidade dos projetos sociais no processo de construção do protagonismo?

O Plano Nacional da Juventude descreve que o protagonismo juvenil é toda a ação política em que os jovens são os atores principais:

Ser reconhecido como ator social estratégico implica a integração social, a participação, a capacitação e a transferência de poder para os jovens como indiví- duos e para as organizações juvenis, de modo que tenham a oportunidade de tomar decisões que afetam as suas vidas e o seu bem-estar. Significa passar das tradicionais políticas destinadas à juventude, isto é, políticas concebidas pelos governos direcionadas ao jovem, para as políticas concebidas e elaboradas com a participação direta ou indireta dos jovens, por meio de estruturas jurídicas reconhecidas pelo Poder Público, como conselhos e coordenadorias da juventude (Novaes, Cara, Silva, \& Papa, 2006, p. 45).

Dessa forma, o jovem protagonista existente no discurso dos projetos sociais é aquele que se tornará um sujeito crítico, politicamente ativo e responsável por modificar sua própria realidade. Porém, os mesmos projetos que discursam sobre possibilitar o reconhecimento dos jovens atendidos como protagonistas de sua própria realidade negam esses mesmos sujeitos como detentores de saber, negando tal protagonismo. Entre os fatores que apontam para esse cenário está o fato de que os jovens nem sempre são chamados para construir, juntamente com os idealizadores dos projetos, as mudanças e ações que desejam, seja no próprio projeto ou mesmo no bairro ou município.

Segundo Abad (2002), as demandas ditas de juventude são quase sempre especificadas por determinados setores da sociedade, integrados em sua maioria por adultos que nem sempre são sensíveis aos pontos de vista dos jovens. Percebem-se, portanto, duas variáveis: de um lado, se espera que o jovem se torne protagonista e exerça suas práticas de cidadania e, de outro, é notória a falta de espaço para que se execute, de fato, o protagonismo juvenil. Diante disso encontram-se outras fragilidades dos projetos sociais, como a dificuldade de aderência dos jovens às atividades propostas, o que talvez possa ser explicado pela não existência da ótica juvenil na elaboração delas.

Logo que cheguei ao ginásio, minha apreensão inicial era saber se alguém viria, pois percebi que estava vazio, e vi que quase nenhuma menina tinha vindo para aula de futsal. Nesse momento, minha ansiedade aumentou, porque, ao longo dos meses, no projeto era comum relatos da equipe de que os adolescentes não tinham interesse nas atividades propostas, ou então pouco envolvimento dos alunos (Participante 3, diário de campo, 29 de maio de 2017). 
Corroborando essa discussão, as autoras Frezza, Maraschin e Santos (2008) apontam a importância de se desenvolver mecanismos e estratégias participativas dos próprios jovens no planejamento, na execução e na análise dos projetos sociais, a fim de evitar que sejam mais comprometidos com as dinâmicas de governo e de controle de indivíduos e populações do que com a construção da cidadania e da inclusão dos indivíduos e grupos em uma sociedade de direitos (Pinto \& Oliveira, 2017).

\section{Ensaios de um despertar: por onde começa a transformação?}

Em seguida, um dos participantes questionou:

"Por que as ruas estão cheias de senegaleses e haitianos? Essas pessoas vêm para cá porque têm seus direitos violados, né? Eu vejo. Tem muitos deles ali do lado do shopping vendendo coisas." (Participante 14, diário de campo, 15 de maio de 2017).

Durante os encontros, os participantes estudaram os artigos da DUDH e realizaram o exercício de relacionar o material a alguma situação cotidiana. A fala acima revela que os participantes passaram a reconhecer tanto os direitos quanto violações, como ao se referir aos refugiados e migrantes e aos motivos do seu refúgio, muitas vezes relacionados a guerras. As oficinas de educação em direitos humanos se tornaram um instrumento de manifesto, pois aos poucos todos que estavam envolvidos foram aprendendo a "lutar". Os participantes compartilhavam, cada vez mais, suas insatisfações, suas angústias, seus questionamentos e até denúncias sobre suas realidades. Percebeu-se que não era mais comum naturalizar algumas situações que eles, sua comunidade e as populações, em geral, enfrentavam. A manifestação veio através das palavras, "da caneta e do papel" e, principalmente, da empatia, pois agora também reconheciam o outro como um sujeito de direitos.

Em meio a esse contexto houve o convite aos participantes para ocupar uma escola. Esse convite não estava vinculado somente ao belo discurso de Ana Júlia ${ }^{1}$, ao qual os participantes assistiram em um vídeo em um dos encontros, mas também às discussões que surgiram em quase todos os momentos sobre as insatisfações dos participantes com suas escolas e sobre os sentimentos de tentar mudar o rumo das coisas. Conforme falou um dos participantes em uma das oficinas: "Lá na escola os alunos não têm vez, a gente nunca pode dar a nossa opinião" (Participante 2, comunicação pessoal, 5 de junho de 2017).

Porém, diante desse convite, é preciso refletir sobre o fato de que "ao mesmo tempo que os grupos são os objetivos principais das propostas instituintes, eles são os próprios meios para realizá-las" (Baremblitt, 1996, p. 17). O convite ocorreu no terceiro encontro e, ao final das oficinas, os adolescentes também já haviam pensado em ações por meio do grêmio estudantil.

Esse despertar para a transformação não ocorreu somente com os participantes das oficinas. A construção dessa proposta abriu caminhos desconhecidos em relação ao "fazer da psicologia" face à temática dos direitos humanos, e por se tratar de caminhos pouco percorridos, foram encontrados desfechos inesperados. Notou-se um vasto campo de atuação para a psicologia, observando-se efeitos positivos e novas possibilidades de atuação em diversos contextos. Também notou-se que é possível e necessária a construção de uma psicologia que se afirme crítica à problematização dos contextos micro e macrossociais na totalidade histórica da vida cotidiana, ou seja, que considere a "importância e a potência da participação cidadã na construção de condições verdadeiramente democráticas de existência" (Silva \& Carvalhães, 2016, p. 251). Além disso, notaram-se algumas certezas e, concomitantemente, novos questionamentos, agora não mais sobre qual o papel da psicologia diante da temática dos direitos humanos, mas sobre quais os "limites" desse fazer da psicologia.

Nesse sentido, as autoras Silva e Carvalhães (2016) mencionam outras possibilidades e novos "limites" para o fazer da psicologia, considerando que sua intervenção nas esferas dos direitos e das políticas públicas demanda o "trabalho em rede", ou seja, a abertura de interlocuções interdisciplinares e comunitárias, demandando a articulação entre os saberes e os diálogos com profissionais e usuários, cujos olhares são diferentes. Nesse sentido, relata-se um dos desfechos das oficinas de educação em direitos humanos:

No encerramento das oficinas, comentamos com os adolescentes que, enquanto projeto social, tentaríamos levar algumas sugestões para as escolas e perguntamos o que eles gostariam que fosse falado. Os adolescentes falaram que gostariam muito de ter oficinas como aquelas nas escolas para poderem falar

\footnotetext{
${ }^{1}$ Ana Júlia foi uma estudante secundarista que realizou uma fala na Assembleia Legislativa do Paraná sobre as ocupações: https:// www.youtube.com/watch?v=pUQLs9y_fx4
} 
sobre o seu dia a dia e sobre os direitos humanos. À vista disso, durante a reunião com a equipe do projeto social, que ocorria semanalmente, comentamos sobre o encerramento das oficinas e sobre os debates que os encontros proporcionaram e questionamos a equipe sobre as ações que poderíamos tomar em relação ao que os participantes solicitaram. Entre as ações, a equipe decidiu levar as sugestões dos participantes e a apresentação da proposta das oficinas de Educação em Direitos Humanos para uma reunião de rede, na qual estariam presentes alguns representantes das escolas e de toda a rede do território em que os adolescentes moravam. (Pesquisadora, diário de campo, 21 de julho de 2017).

Tendo em vista o compromisso ético-social e político da psicologia, foram discutidas com a equipe do projeto social as ações que poderiam ser tomadas para promoção e garantia dos direitos humanos dos participantes das oficinas em seus contextos escolares. A decisão de buscar outras ações diante do que foi evidenciado nas oficinas demonstra que a educação em direitos humanos implica também assumir um compromisso com a cidadania e, para isso, requer a constituição de alianças entre os membros da sociedade civil e do Estado, formando redes que fortalecem a defesa dos direitos humanos (Secretaria de Direitos Humanos da Presidência da República, 2013). Além disso, Bock e Gianfaldoni (2010) mencionam que é necessário oferecer visibilidade em diferentes espaços e promover trabalhos que relacionem psicologia e direitos humanos a fim de reafirmar o compromisso da psicologia com essa área, além de buscar auxiliar profissionais, como os professores, a exercer a prática da educação em direitos humanos.

Diante da articulação com o projeto social, no dia 14 de agosto ocorreu uma reunião de rede com o objetivo de discutir algumas pautas que os adolescentes trouxeram para as oficinas e a importância de trabalhar a educação em direitos humanos nas escolas e demais instituições do município, como em projetos e ONG. Na reunião, estavam presentes a Secretária de Educação do município em que ocorre o projeto social mencionado, um representante da Secretaria de Desenvolvimento Social e Direitos Humanos, psicólogos, enfermeiros e assistentes sociais que atuam no Centro de Atendimento Psicossocial (Caps), no Centro de Referência de Assistência Social (Cras) e no Centro de Referência Especializado de Assistência Social (Creas), além de agentes de saúde, orientadoras e coordenadoras pedagógicas das escolas do bairro em que ocorreram as oficinas.

\begin{abstract}
Enquanto falávamos do quanto os adolescentes haviam participado dos grupos e comentado sobre sua vontade de discutir direitos humanos na escola, a sala de reuniões ficava em um silêncio extremo. $O$ objetivo daquela reunião era conversar com os profissionais no sentido de incentivá-los de que é possivel trabalhar direitos humanos nas escolas e de informar os beneficios que esse trabalho traz para a comunidade local e escolar (Pesquisadora, diário de campo, 14 de agosto de 2017).
\end{abstract}

Os olhares e o silêncio durante a reunião não eram um fato comum, bem como ocupar um espaço como aquele para tratar do tema. Silva e Carvalhães (2016) afirmam que, diante da ocupação de novos espaços de atuação, os profissionais da psicologia observam a necessidade de abandonar, por vezes, alguns modelos tradicionais, ousando experimentar novas formas de exercício profissional. Freitas (2007) corrobora a discussão, afirmando que o diálogo com os usuários e suas comunidades, a construção de ações conjuntas e solidárias e o fortalecimento de redes de solidariedade com foco na articulação de projetos coletivos são alguns dos grandes desafios que dimensionam a prática da psicologia.

Ao fim da apresentação da proposta de oficinas de Educação em Direitos Humanos na reunião de rede, os profissionais continuaram em silêncio por um longo período. Após alguns minutos, uma profissional da rede que estava presente comentou sobre seu conhecimento da importância de dialogar sobre esse tema, ao mesmo tempo em que se sentia impotente para abordar esse assunto. A profissional compartilhou sua angústia de estar há poucos meses trabalhando em um bairro $e$ perceber que não há nenhum equipamento, como praças, saneamento, entre outros. Ela contou que não se sentia encorajada para falar sobre direitos sabendo que ali não há nada para oferecer e que todos estão mergulhados na violência decorrente dessas violações. Assim, outros profissionais da rede comentaram sobre a necessidade de realizar capacitações com as escolas para que essas temáticas sejam abordadas e comentaram que estavam se sentindo muito reflexivos, tentando entender 
por que as escolas haviam esquecido a importância de trabalhar direitos humanos (Pesquisadora, diário de campo, 14 de agosto de 2017).

Como visto no relato do diário de campo, a participação na reunião de rede possibilitou um espaço de reflexão sobre a temática direitos humanos nas escolas, bem como permitiu que os profissionais envolvidos percebessem os adolescentes como sujeitos interessados em espaços de fala e assuntos coletivos. Além dos comentários mencionados, os profissionais compartilharam, durante a reunião, percepções sobre a dificuldade de elaborar atividades sobre as quais os adolescentes tenham interesse. Diante disso, foi comentada a importância de utilizar metodologias que oportunizem a atuação dos adolescentes como agentes de levantamento, organização e mobilização das propostas. Também foi proposto aos profissionais que repensem ações para que proporcionem de fato o protagonismo juvenil.

A reunião de rede, em consequência, acabou se tornando outro espaço para promoção dos direitos humanos, além de contribuir para uma nova possibilidade de atuação da psicologia diante dessa temática. Por fim, as mobilizações propostas pela psicologia, tanto nas oficinas quanto nessa reunião, demonstram a necessidade de que os psicólogos se reconheçam como agentes políticos com condições de contribuir para o devido reconhecimento dos próprios moradores das localidades em que atuam sobre suas condições de sujeitos de direitos. Ademais, espera-se que esses profissionais também possam auxiliar construções coletivas de mudanças na realidade dessas comunidades (Silva \& Carvalhães, 2016). Diante dessas ações, será que já se torna possível visualizar começos para as transformações desejadas? Talvez esse seja apenas um ensaio de uma transformação, porém, evidencia que ao articular psicologia, política e direitos humanos é possível abrir espaços para outras questões, principalmente entendendo que tal combinação possibilita produzir efeitos poderosíssimos no mundo (Coimbra, 2000).

\section{Considerações finais}

Diante do compromisso com a cidadania e das vivências compartilhadas nas oficinas, verificaram-se discrepâncias e violações no que se refere ao lugar que a escola e os projetos sociais vêm ocupando no dia a dia dos adolescentes. Observou-se as escolas como espaços com propósitos disciplinadores e de anulação da subjetividade, em vez de locais que promovem o desenvolvimento dos jovens enquanto cidadãos, onde há o compartilhamento de práticas de convivência e solidariedade humana.

O fechamento da análise se dá com o compartilhamento de alguns resultados que emergiram das oficinas de educação em direitos humanos. A discussão apresentada visa demonstrar a importância que os espaços de trocas sobre a temática têm na vida dos jovens, principalmente no sentido de promoção e garantia dos direitos. Além disso, verificou-se a relevância da atuação da psicologia junto às políticas públicas, em especial por servir como uma área de conhecimento capaz de auxiliar os profissionais da rede e os próprios participantes na construção de políticas públicas e ações para a juventude.

Por fim, este estudo contribui para a reflexão das práticas da psicologia enquanto profissão comprometida socialmente e atuante nas políticas públicas. $\mathrm{O}$ relato demonstrou a necessidade de abrir novos prismas de estudos, pesquisas, ações e compartilhamento de experiências nesses contextos. Percebe-se, através deste debate, a necessidade de desenvolver o conceito de direitos humanos entre os psicólogos, professores e profissionais de outras áreas, sendo preciso oferecer visibilidade aos trabalhos e às experiências de formação que incluam interfaces entre psicologia e direitos humanos (Bock \& Gianfaldoni, 2010). É preciso olhar para o fazer da psicologia, para os jovens, para as comunidades, para tudo aquilo que é humano. É preciso permitir se reinventar, movimentar-se por onde houver vida, tentando torná-la, pouco a pouco, mais humana.

\section{Referências}

Abad, M. (2002). Las políticas de juventud desde la perspectiva de la relación entre convivencia, ciudadanía y nueva condición juvenil. Última década, 10(16), 117152. http://dx.doi.org/10.4067/S0718-22362002000100005

Araújo, L. F. S., Dolina, J. V., Petean, E., Musquim, C. A., Bellato, R., \& Lucietto, G. C. (2013). Diário de pesquisa e suas potencialidades na pesquisa qualitativa em saúde. Revista Brasileira de Pesquisa em Saúde, 15(3), 5361. https://doi.org/10.21722/rbps.v15i3.6326

Baremblitt, G. (1996). Compêndio de análise institucional (3a ed.). Rosa dos Tempos. 
Bernardi, C. M. C. N. (2010). A formação em psicologia: Ética, diretrizes curriculares e direitos humanos. IV Simpósio Internacional e VII Fórum Nacional de Educação, Torres, RS.

Bock, A. M. B., \& Gianfaldoni, M. H. T. A. (2010). Direitos humanos no ensino de psicologia. Psicologia Ensino $e$ Formação, 1(2), 97115.

Charão, C. (2001, 15 de março). Consulados dão apoio financeiro a projetos de ONGs brasileiras. O Estado de São Paulo, p. 15.

Coimbra, C. M. B. (2000). Psicologia, direitos humanos e neoliberalismo. Revista Psicologia Política, 1(1), 139148. http://www.fafich.ufmg.br/ psicopol/psicopol/artigos_pub/artigo_9.pdf

Costa, J. C., Oliveira, P. A., \& Ferrazza, D. A. (2014). Psicologia social e direitos humanos: A atuação da psicologia diante da Ditadura Militar e das manifestações atuais no Brasil. Revista de Psicologia da IMED, 6(2), 7080. https:// dialnet.unirioja.es/descarga/articulo/5155074.pdf

Dallari, D. A. (2008). Direitos humanos: Sessenta anos de conquistas. Revista Direitos Humanos, 1(1), 8-11. http:// www. dhnet.org.br/dados/revistas/a_pdf/revista_sedh_dh_01.pdf

Dazzani, M. V. M. (2010). A psicologia escolar e a educação inclusiva: Uma leitura crítica. Psicologia: Ciência e Profissão, 30(2), 362375. http://dx.doi.org/10.1590/S1414-98932010000200011

Falconer, A. P. (1999). A promessa do terceiro setor: Um estudo sobre a construção do papel das organizações sem fins lucrativos e de seu campo de gestão [Dissertação de Mestrado, Universidade de São Paulo]. La Sociedad Civil en Línea. http://www.lasociedadcivil.org/wp-content/uploads/2014/11/andres_falconer.pdf

Freire, P. (1997). Pedagogia da autonomia: Saberes necessários à prática educativa. Paz e Terra.

Freitas, M. F. Q. (2007). Intervenção psicossocial e compromisso: Desafios às políticas públicas. In A. M. Jacó-Vilela, \& L. Sato, Diálogos em psicologia social (pp. 370386). Evangraf.

Frezza, M., Maraschin, C., \& Santos, N. S. (2008). Juventude como problema de políticas públicas. Psicologia \& Sociedade, 21(3), 313323. https://doi.org/10.1590/S0102-71822009000300004

Gadotti, M. (1993). Histórias das ideias pedagógicas. Autores Associados.

Gallo, S. (2004). Repensar a educação: Foucault. Educação \& Realidade, 29(4), 7997. http://seer.ufrgs.br/index.php/ educacaoerealidade/article/view/25420/14746

Hunt, L. (2009). A invenção dos direitos humanos: Uma história. Companhia das Letras.

Iamamoto, M. V. (2004). O serviço social na contemporaneidade: Trabalho e formação profissional. Cortez.

Landim, L. (1993). A invenção das ONGs: Do serviço invisível à profissão impossível [Tese de Doutorado, Universidade Federal do Rio de Janeiro]. Sinapse Biblioteca Virtual do Desenvolvimento Social. https://sinapse.gife.org.br/ download/invencao-das-ongs-servico-invisivel-profissao-impossivel

Lei n. 9.394, de 20 de dezembro de 1996. (1996, 23 de dezembro). Estabelece as Diretrizes e Bases da Educação Nacional. Diário Oficial da União. http://www.planalto.gov.br/ccivil_03/leis/L9394.htm

Mattos, P. H. C. (2003). A escola da não-violência. Jornal Mundo Jovem, (421), 912.

Maturana, H. (1999). Emoções e linguagens na educação e na política. Editora UFMG.

Minayo, M. C. S. (2001). Pesquisa social: Teoria, método e criatividade (18a ed.). Vozes.

Moura, E, P. G., \& Zucchetti, D. T. (2010). Educação além da escola: Acolhida de outros saberes. Cadernos de Pesquisa, 40(140), 120. https://doi.org/10.1590/S0100-15742010000200016

Novaes, R. C. R, Cara, D. T., Silva, D. M., \& Papa, F., C. (Orgs.). (2006). Política Nacional de Juventude: Diretrizes e perspectivas. Congresso Nacional de Juventude, Fundação Friedrich Ebert.

Pinto, R. M. N., \& Oliveira, C. B. (2017). Esporte, infância e juventude despossuída: Uma análise das ONGs como acontecimento discursivo. Revista Brasileira de Ciências do Esporte, 39(1), 3948. http://dx.doi.org/10.1016/j.rbce.2016.01.013

Piovesan, F. (2004). Direitos sociais, econômicos e culturais e direitos civis e políticos. Sur Revista Internacional de Diretos Humanos, 1(1), 2047. http://dx.doi.org/10.1590/S1806-64452004000100003 
Rosato, C. M. (2011). Direitos humanos para quem? Uma análise de discursos jornalísticos em Pernambuco e São Paulo (1987 e 1997) [Dissertação de Mestrado, Universidade Federal de Pernambuco]. Attena Repositório Digital da UFPE. http:// repositorio.ufpe.br/handle/123456789/8483

Secretaria de Direitos Humanos da Presidência da República. (2013). Educação em Direitos Humanos: Diretrizes Nacionais. http://portal.mec.gov.br/index.php?option=com_docman\&view=download\&alias=32131-educacao-dh-diretrizesnacionais-pdf\&Itemid=30192

Silva, R. B., \& Carvalhães, F. F. (2016). Psicologia e políticas públicas: Impasses e reinvenções. Psicologia \& Sociedade, 28(2), 247256. https:// doi.org/10.1590/1807-03102016v28n2p247

Souza, R. M. (2006). O discurso do protagonismo juvenil [Tese de Doutorado, Universidade de São Paulo]. Biblioteca Digital USP. http://www.teses.usp.br/teses/disponiveis/8/8132/tde-25042007-115242/pt-br.php

Tavares, C. (2013). Política de educação em direitos humanos na rede pública estadual de Pernambuco: Um processo em construção. XXVI Simpósio da ANPAE, Recife. http://www.anpae.org.br/simposio26/1comunicacoes/CelmaTavares-ComunicacaoOral-int.pdf

Veiga-Neto, A. (2006). Na oficina de Foucault. In J. Gondra, \& W. Kohan (Orgs.), Foucault 80 anos (pp. 7991). Autêntica.

Franciéli Katiúça Teixeira da Cruz Severo

Graduanda de Psicologia na Universidade Feevale, Novo Hamburgo - RS. Brasil.

Email: francielipsi@gmail.com

(1) https://orcid.org/0000-0002-4077-2983

Carmem Regina Giongo

Professora do Curso de Psicologia da Universidade Feevale, Novo Hamburgo - RS. Brasil.

E-mail: carmemgiongo@feevale.br

(1) https://orcid.org/0000-0001-7335-8511

Eliane Perez Gonçalves de Moura

Professora do Curso de Psicologia da Universidade Feevale, Novo Hamburgo - RS. Brasil.

E-mail: elianapgm@feevale.br

(1) https://orcid.org/0000-0001-7106-0770

Endereço para correspondência:

Universidade Feevale, Departamento de Psicologia, segundo andar, ICH. Rodovia ERS-239, 2755. CEP: 93525-075.

Novo Hamburgo - RS. Brasil.

Recebido 03/10/2018

Aceito 29/07/2019

Received 10/03/2018

Approved 07/29/2019

Recibido 03/10/2018

Aceptado 29/07/2019 
Psicologia: Ciência e Profissão 2021 v. 41 (n.spe 4), e214978,1-14.

Como citar: Severo, F., Giongo, C., \& Moura, E. (2021). Educação em direitos humanos na perspectiva de adolescentes participantes de um projeto social. Psicologia: Ciência e Profissão, 41 (n.spe 4), 1-14. http://doi.org/10.1590/1982-3703003214978

How to cite: Severo, F., Giongo, C., \& Moura, E. (2021). Education in human rights under the perspective of adolescents participating in a social Project. Psicologia: Ciência e Profissão, 41 (n.spe 4), 1-14. http:// doi.org/10.1590/1982-3703003214978

Cómo citar: Severo, F., Giongo, C., \& Moura, E. (2021). Educación en derechos humanos en la perspectiva de adolescentes participantes en un proyecto social. Psicologia: Ciência e Profissão, 41 (n.spe 4), 1-14. http://doi.org/10.1590/1982-3703003214978 